Doi: $\underline{\text { dx.doi.org/10.17921/2525-5320.2016.123-133 }}$

\title{
HISTÓRIA LOCAL E O MÉTODO DE AULA-OFICINA: BREVES CONSIDERAÇÕES
}

\author{
Paulo Sérgio Micali Junior* - UEL \\ Taiane Vanessa da Silva* - UEL
}

Palavras-chave: Ensino de História. História Local. Aula-Oficina.

\section{INTRODUÇÃO}

O século $X X$, para a historiografia, foi marcado por uma série de reformulações teórico-metodológicas que adquiriram maior vigor a partir da década de 1970. Uma série de críticas à influência positivista na disciplina histórica, recorrentes desde 1920 entre os Annales, culminou no surgimento da Histoire Nouvelle (História Nova), uma corrente historiográfica que propunha à historiografia "alargar" seu campo de interesses, enriquecer seu referencial teórico-metodológico e, consecutivamente, romper com os limites circunscritos às pesquisas concernentes aos "grandes homens e acontecimentos" a partir de documentos escritos tidos como oficiais.

Aquelas correntes tiveram papel fundamental para que se repensasse o ofício do historiador. A propósito, atualmente não mais contamos, quase que exclusivamente, com pesquisas direcionadas ao politico, ao econômico num recorte macrocósmico ou às epopeias vivenciadas por famosas figuras históricas como Napoleão, Júlio César ou Alexandre. Em outras palavras, o número de pesquisas e trabalhos que fogem as ortodoxias referentes a história, que vinha sendo feita até então, vem crescendo exponencialmente. Hoje, temas como as mentalidades, vida privada e práticas culturais são investigados a partir de fontes orais, periódicas e fotográficas nos ambientes escolar e acadêmico, e isso, vale ressaltar, há poucas décadas atrás, seria impensável; soaria como um absurdo.

Agora, não mais discutiremos os processos transformatórios sofridos pela história, pois fugiria ao nosso tema. Foquemos no que significou, para alunos e professores, a renovação dos interesses, ferramentas e problemas concernentes à disciplina da história: grosso modo, significou uma melhora bastante positiva, afinal,

\footnotetext{
*E-mail: p.s.micali@hotmail.com

*E-mail: taaivanessa@hotmail.com
} 
tornou-se-lhes possível ampliar seus horizontes. Todavia, como se deu essa melhora? Como os horizontes foram ampliados?

Buscando melhor elucidar aquelas questões, estabeleceremos um recorte ainda mais específico em nossa discussão; tratemos do ensino da História local. No Brasil, essa disciplina faz parte dos currículos escolares desde 1990, presença essa que, para Zamboni, significa uma problematização das "[...] identidades locais, das coletivas, a identificação e aceitação das diferenças, das aproximações e dos distanciamentos" (2005, p.15), ou seja, a história tornou-se "mais palpável", mais "próxima", deixou de privilegiar somente aos governantes, grandes personalidades e possibilitou aos docentes e discentes, pessoas comuns, enxergarem-se enquanto agentes participativos da história.

O estudo da história a partir de um microrrecorte, no entanto, não é novidade. Carlo Ginzburg, por exemplo, publica seu O Queijo e os Vermes ainda na década de 1970, obra esta que talvez represente uma das maiores referências dentro da microhistória. Já o emprego do microrrecorte em sala de aula, isso constitui um campo ainda jovem, em estruturação e que merece de nossa parte, historiadores, um olhar mais aguçado, como o afirmam Lima e Zarpelão (2013, p.199)

[...] novas propostas surgiram no contexto escolar e acadêmico e, nesse sentido, o estudo da história local, regional e do cotidiano ganhou força, servindo especialmente para aproximar a disciplina de História da realidade vivida pelos alunos. Transmitindo essa ideia para o Estado do Paraná [...] percebemos que ela pode ser considerada como uma construção humana, passível de análise e sujeita a articulações com contexto mais amplos. Entretanto, para compreender essa construção, ligada a complexas relações sociais, que abrangem os pactos políticos, econômicos, naturais, culturais, entre outros, é necessário uma postura investigativa do docente de História.

A postura investigativa por parte do docente, levantada por Lima e Zarpelão, énos peça-chave neste contexto já que, apesar dos benefícios proporcionados por essa renovada disciplina histórica, ela também apresenta uma série de perigos e problemas, assim como qualquer outra. Faz-se necessário ao historiador, portanto, adotar uma postura incrédula, crítica, assim como a de um detetive, a fim de que as fontes de estudo não "nos enganem". De acordo com o historiador francês Jacques Le Goff, "o dever principal do historiador é a crítica do documento - qualquer que ele seja" (LE GOFF, 1992, p.470), ou seja, documentos não são "inocentes". Estes são construtos humanos, portanto são dotados de significados e intenções, fatores esses 
que, quando não considerados, conduzem-nos ao engano, a frivolidade.

Isto posto, a proposta de ensino elaborada por Isabel Barca apresenta-se auspiciosa. Assim, propomo-nos com este artigo estabelecer algumas considerações acerca do modelo de aula-oficina † proposta por Barca (2004), apontando as virtudes desta metodologia ao tratarmos de história local em sala de aula.

O presente texto visa, portanto, apresentar o método de aula-oficina proposto por Isabel Barca (2004) e os benefícios da utilização e análise de variados documentos históricos em sala de aula como caminhos vantajosos para o ensino de História local. É valido ressaltar que, assim como Ulpiano Toledo Bezerra de Meneses (2003), não acreditamos em um conceito universal que defina cidade ou local. Desta forma, consideramos para esta pesquisa que cada local apresenta especificidades diferenciadas, logo não visamos apresentar a análise de histórias locais específicas, mas sim métodos e teorias que possam ajudar no estudo destas.

De acordo com Ernesta Zamboni, durante a década de 1990, uma série de pensadores como Roger Chartier, Robert Darton e Carlo Ginzburg "[...] deram sustentação a propostas de ensino que usava a literatura como uma fonte documental e necessária na construção de um cenário da época, isto é, como uma nova linguagem para o ensino de História" (2005, p.14-15). Outra proposta também muito recorrente naquele período refere-se aos estudos da história local, que figura nos currículos escolares brasileiros desde a década de 1990, e por meio dos quais se busca problematizar tradições e memórias de pessoas e lugares.

O ensino da História local em escolas brasileiras revela-se bastante promissor, já que possibilita aos alunos e professores fugirem

[...] de um enfoque tradicional da História da cidade, e atingir a História dos migrantes e imigrantes, dos trabalhadores rurais e urbanos; outro caminho é a releitura dos temas tradicionais da História local, propiciando uma abordagem crítica e alternativa, que se beneficia do enfrentamento entre a artificialidade da História construída e da memória, isto é, a da experiência dos indivíduos (CERRI, 2013, p.37).

No entanto, o emprego de temas concernentes ao local apresenta algumas dificuldades. Abordar, em sala de aula, práticas esportivas ou culturais características de determinado local, por exemplo, pode constituir uma tarefa hercúlea quando há escassez de fontes históricas disponíveis, e esse tipo de

\footnotetext{
† Voltada para o ensino de História.
} 
ausência é muito comum. Dessa forma, a fim de superar aquela dificuldade, faz-se necessário o emprego de uma metodologia de ensino que comtemple uma multiplicidade de fontes (como filmes, jornais, entrevistas e objetos) de forma que estas constituam significados aos alunos enquanto no processo de ensinoaprendizagem.

\section{MATERIAL E MÉTODOS}

Entendemos a aula-oficina como um modelo que "[...] privilegia a construção de uma aula inicialmente organizada por um tema e um conjunto de objetivos a serem atingidos com o debate em sala de aula" (SOUSA, s/d). Feitas essas definições iniciais, dá-se continuidade à aula-oficina a partir de três procedimentos: levantamento dos conhecimentos prévios dos alunos, elaboração de aula(s)-oficina condizente(s) às respostas obtidas naquele e, por fim, realização de uma atividade final que constituirá o produto da(s) aula(s)-oficina.

Embora o estabelecimento de um relato de experiência não configure em nossos planos, apresentar, mesmo que brevemente, algumas considerações concernentes a uma aula-oficina aplicada por um dos autores deste artigo revelaram-se uma possibilidade tentadora. Ressaltamos: não buscamos elaborar um relato de experiências, mas trazer algumas considerações para fins elucidativos.

A experiência em questão configura-se entre as responsabilidades do bolsista do Programa Institucional de Bolsas de Iniciação à Docência (Pibid) de história da Universidade Estadual de Londrina (UEL), que aconteceu no ano de 2014, num colégio da rede estadual do Paraná com uma turma de $8^{\circ}$ ano. Na ocasião, o tema abordado girou em torno da prática esportiva do boxe em Londrina, e tomamo-la enquanto circunscrita à disciplina de história local.

A aula-oficina propriamente dita fora dividida em três momentos, basicamente. Num primeiro, realizou-se o levantamento das ideias tácitas dos alunos. Barca sugere que esse levantamento seja realizado "[...] no momento inicial da aula, que numa situação de rotina é feito informalmente [...]" (2004), mas nada impede que o seja feito de forma sistemática a partir de um questionário ou tarefa escrita. Nessa etapa, o professor tem de assumir o papel de investigador social, ou seja, ele deve explorar o mundo conceitual de seus alunos não para corrigi-los, mas para melhor compreende-los e, assim, proporcionar-lhes educação onde prevaleça o diálogo, a fim de que o processo de ensino-aprendizagem caracterize-se enquanto "via de mão 
dupla". Talvez seja essa uma das principais aspirações do modelo proposto por Barca: alunos e professores atuando juntos no processo de construção de conhecimentos.

Em adição, devemos levar em consideração, de acordo com Lana Mara de Castro Siman (2004), que os alunos vivenciam desde cedo os efeitos de visões estereotipadas sobre classes sociais, culturas e grupos, influenciadas por relações sociais ou até mesmo por visões historiográficas dominantes, dificultando assim a desconstrução ou reconstrução do conhecimento por parte do professor no espaço formal e informal da aprendizagem. Por isso, cabe ao professor a desconstrução (do senso comum) e a reconstrução de conhecimento (histórico, formulado sobre outras concepções).

Em outras palavras, o levantamento de conhecimentos prévios e a análise das fontes deverá ser feita com a mediação dos professores, com o intuito de possibilitar uma relação dialógica com os alunos, "visto que o discurso é formado por 'metade nossa e metade do outro"' (SIMAN, 2004, p.88), construindo, assim, a matéria prima para a produção de um novo significado. Logo, a ênfase no dialogismo e, consequentemente, na troca de experiência entre mediadores e alunos, resultam na autonomia do estudante e na investigação crítica acerca do conteúdo estudado. Além disso, de acordo com Siman (2004), a função dialógica torna os discentes sujeitos ativos do processo de ensino e aprendizagem.

Ainda sobre a aula-oficina, vale ressaltar que reservar o tempo de uma aula completa para que os alunos respondam o questionário com calma e, posteriormente, possam discutir suas opiniões, referentes àquelas questões, de forma oral apresenta-se enquanto uma riquíssima oportunidade, afinal, o modelo de aula-oficina preza pelo diálogo. Feito isso, é possível identificar o grau de interação dos alunos para com o tema, grau este que possibilitará ao professor estipular um número de aulas necessárias além de adaptá-las de acordo com as necessidades apresentadas pelos alunos. Seria absurdo, por exemplo, oferecer aos alunos uma única aula-oficina e esperar deles conhecimentos avançados naquilo que mal conhecem.

É sugerível, então, durante as aulas, que se utilize uma rica variedade de fontes de estudos para que se desenvolva o raciocínio histórico dos alunos. A importância dos mediadores culturais enquanto no desenvolvimento do processo de ensino/aprendizagem, a propósito, é descrito por Siman (2004, p.88) no seguinte 
excerto:

\begin{abstract}
Para que o ensino de História, todavia, seja levado a bom termo [...] tornase necessário que o professor inclua, como parte constitutiva do processo de ensino/aprendizagem, a presença de outros mediadores culturais, como os objetos da cultura, material, visual ou simbólica, que ancorados nos procedimentos de produção do conhecimento histórico possibilitarão a construção do conhecimento pelos alunos, tornando possível "imaginar", reconstruir o não-vivido diretamente, por meio de variadas fontes documentais.
\end{abstract}

Vídeos, imagens, fotos, objetos, filmes, entrevistas, luvas de boxe e matérias de periódicos, por exemplo, são apenas algumas das fontes que podem ser utilizadas em sala de aula. Isso não significa, no entanto, que o livro didático e/ou materiais tidos como "ortodoxos", num ambiente escolar, estejam sendo desconsiderados e/ou desvalorizados; apenas acreditamos que uma maior variedade de fontes catalise as operações cognitivas dos alunos, estimulando-Ihes a imaginação e possibilitando-lhes, consequentemente, uma melhor aprendizagem (SIMAN, 2004).

Isto posto, segundo Barca (2001) não é fácil saber, a princípio, o que os alunos pensam sobre História. No entanto, seu estudo tem como resultado a compreensão de que é possível motivar argumentações sobre as versões e fontes históricas. Logo, vê-se a necessidade de trabalhar, em sala de aula, com várias perspectivas históricas sobre um mesmo assunto por meio de fontes variadas. Tal perspectivas pode contribuir, por exemplo, para a superação de visões estereotipadas sobre determinados assuntos relacionados a história local. As perspectivas de Paula Dias (2007), por exemplo, também vão ao encontro das ideias dos autores apresentados. De acordo com Dias, os alunos são capazes de analisar fontes diversificadas, mesmo que remetam a assuntos que não Ihes são familiares, caso sejam orientados de forma correta.

Por fim, é hora da avaliação, tarefa esta que constituirá o produto da(s) oficina(s). De acordo com Rosado e Silva, uma avaliação "[...] deve ser entendida como uma forma de concretizar um balanço no final de um ciclo de ensino (e aprendizagem) [...]" (2010). Já Isabel Barca (2004) aprofunda-se mais no assunto, alertando-nos sobre os reducionismos bastante presentes em processos avaliativos. 
de informação (completo versus incompleto), uma dicotomia válida para o registro de factualidade mas questionável em itens mais elaborados. Conceitos de relatividade e objetividade crítica vieram complexificar os critérios sobre a verdade científica, e hoje, poderemos avaliar os conhecimentos como mais ou menos válidos: científicos, aproximados, de senso comum ou alternativos. Esta visão gradual é importante no que diz respeito à avaliação formativa, se queremos valorizar pontos de partida diferentes e assim promover uma progressão individualizada dos alunos. E, como diz Peter Lee, aprendizagem dever ser considerada gradual, por vezes oscilante. Não é uma questão de tudo ou nada... (BARCA, 2004).

A avaliação, portanto, pode caracterizar-se enquanto processo gradual, possuindo caráter formativo e podendo fugir ao maniqueísmo certo $\mathrm{x}$ errado. Extremamente importante, é ela que constituirá o produto ao fim de um processo de ensino/aprendizagem marcado pela valorização dos conhecimentos tácitos dos alunos, pelo diálogo e pelo papel do professor enquanto mediador. A avaliação, a propósito, assim como as aulas, podem e devem ser elaboradas de acordo com as necessidades da turma, desde um desenho para os mais novos até um projeto mais elaborado para os mais maduros.

\section{RESULTADOS E DISCUSSÃO}

Nem todos os historiadores apresentam a mesma assiduidade que os sociólogos enquanto na explanação dos conceitos abordados. "Geração", "memória" e "patrimônio", por exemplo, muitas vezes são empregados pelos historiadores como se a delimitação de suas definições estivesse "dada" e fizesse parte do repertório geral. Esse talvez seja um dos motivos pelos quais os sociólogos acusam-nos de colecionar fatos de forma amadora e míope, prejudicando, portanto, suas análises (BURKE, 2002, p.13) e emprego enquanto no ofício docente. Atentos a esse perigo, propomo-nos a investigar ${ }^{\ddagger}$, além do modelo de aula-oficina (BARCA, 2004), o conceito de local naquilo que tange a pesquisa e o ensino concernentes à disciplina histórica.

Iniciemos pelo conceito de local. De acordo com o dicionário da Academia Brasileira de Letras (2008), local é o que se limita a um lugar. No entanto, essa definição, além de não satisfazer nosso questionamento, direciona-nos a um novo: o que é lugar? Peruzzo e Volpato reconheceram as dificuldades implícitas a essa definição ao destacar que, além do fator espacial, local também implica em "[...]

\footnotetext{
‡ Investigaremos esse conceito ao invés de defini-lo, pois, como veremos a seguir, tamanha a complexidade desta empreitada, extraviar-nos-íamos de nosso objetivo.
} 
características peculiares, que evoca sentimentos de familiaridade e vizinhança, congrega certa identidade e história, hábitos e linguagem comum [...]" (2009, p.145), ou seja, para além de geográfico, o local também é social, pois,

[...] é construído de tal maneira que, quanto mais próximos estiverem os grupos ou instituições ali situados, mais propriedades eles terão em comum; quanto mais afastados, menos propriedades em comum eles terão. As distâncias espaciais - no papel - coincidem com as distancias sociais. (BOURDIEU, 2004, p.153)

Sobre o trabalho com história local em sala de aula, acreditamos que o modelo de aula-oficina seja bastante adequado, pois consiste numa alternativa aos modelos influenciados pelos paradigmas tradicionais, como os de "aula-conferência" e "aulacolóquio". A crítica de Barca contra estes se baseia, principalmente, na desvalorização e/ou não cogitação dos conhecimentos prévios dos alunos para com o processo de ensino-aprendizagem. De acordo com a autora (2004), o modelo de 'aula-conferência' parte do pressuposto de que o professor - tido como único detentor do verdadeiro conhecimento - simplesmente repassa seu saber aos alunos que - tidos como 'sacos vazios a serem preenchidos pela sapiência do docente' devem "[...] receber as mensagens e regurgita-las corretamente em teste escrito". Já com relação ao modelo de ‘aula-colóquio', Barca afirma (2004) que

[...] [nele] o saber pode ser problematizado e partilhado, mas a atenção continua a centrar-se na atividade do professor e nos seus materiais de apoio, mantendo-se na sombra o cuidado a ter com as ideias prévias dos alunos e consequentes tarefas cognitivas a desenvolver por estas aulas. $\mathrm{O}$ pressuposto de que o conhecimento deve ser construído na aula pelos alunos é afirmado como mera retórica, sem concretização nem fundamentação empírica e sistemática.

Sob as perspectivas apresentadas, a inserção da história local, unida às vivências dos sujeitos, implica em memórias escritas, orais, em lugares de memória e na diversidade de fontes históricas, gerando conhecimento acerca da ação de pessoas comuns e o entendimento do entorno sociocultural dos sujeitos. O estudo de fontes relacionadas as memórias, por exemplo,

[...] apresenta-se como base da identidade, pois é por meio dela que chegamos à história local, o que destaca a importância dos vínculos estabelecidos com a família, com a comunidade e demais grupos de convívio (BITTENCOURT, 2004 apud CANDOTI, 2013, p.161).

Logo, de acordo com Rüsen, o objetivo do ensino de História é o 
desenvolvimento da consciência histórica, pois "[...] o raciocínio elaborado com a finalidade de entender as ações individuais e coletivas num contexto de tempo e espaço dão condições para que estes se orientem em sua vida prática no tempo presente [...]" (2001 apud CANDOTI, 2013, p. 160). Assim, o conhecimento histórico viabilizado por meio da reflexão das experiências cotidianas das mudanças e das permanências contribui para a formação de novos olhares sobre o meio em que os docentes vivem.

Segundo Candoti, as práticas propostas por Rüsen (2013, p.160) proporcionam a análise e interpretação de diversas fontes históricas, motivando

[...] o conhecimento mais amplo do passado e suas relações com questões presentes e cotidianas. Isso também contribui para a formação da consciência histórica e do senso de identidade, bem como a valorização da mesma, estabelecendo relações mais humanizadas entre os seus grupos de convívio e as mais diversas representações socioculturais. Mais do que ensinar e aprender História, temos que promover o pensar historicamente.

As fontes utilizadas podem, então, ser tomados enquanto documento/monumento, os quais são, segundo Le Goff (1984) materiais da memória. Os monumentos estão relacionados ao poder e à perpetuação de lembranças para o futuro, simultaneamente, podem evocar o passado, pois são heranças do mesmo. Já os documentos são selecionados pelos historiadores que os caracterizam enquanto provas. Porém, Le Goff alerta sobre a inexistência de documentos inócuos, de forma que todo documento deve ser considerado monumento, pois é produto da sociedade, das relações de poder, de seleções e intencionalidades. Portanto, os documentos/monumentos são resultados do empenho das sociedades históricas para deixar às gerações futuras certa imagem de si própria. A análise de variadas fontes históricas pode, então, gerar conhecimento sobre variadas versões da história local, como a valorização de questões cotidianas ou a reflexão sobre as relações de poder que envolvem uma localidade.

\section{CONCLUSÃO}

As reformulações historiográficas ocorridas ao longo do século $X X$, as quais possibilitaram a diversificação de temáticas e fontes para o estudo da história, influenciaram também o ensino de História e a postura dos professores que se 
dedicam a esta disciplina para com o tratamento dos documentos históricos. Dentro deste contexto, a história local conquistou seu espaço, proporcionando, principalmente, a releitura de temáticas tradicionais, aproximando-se, consecutivamente, do cotidiano e das experiências dos alunos.

A metodologia da aula-oficina proposta por Isabel Barca (2004) contempla a diversidade de fontes históricas como ponte para o conhecimento de variadas versões sobre a história - no caso desta pesquisa, a história local. Em linhas gerais, a aula-oficina se pauta: no levantamento do conhecimento prévio dos alunos, visto que estes não são "tábulas rasas"; na utilização da experiência dos alunos como centro da elaboração da aula; e atividades que, por meio da utilização de documentos históricos, elaborem um produto significativo para a aprendizagem.

\section{REFERÊNCIAS}

ACADEMIA BRASILEIRA DE LETRAS. Dicionário escolar de língua portuguesa. São Paulo: Companhia Editora Nacional, 2008.

BARCA, I. Concepções de adolescentes sobre múltiplas explicações em história. BARCA, I. (Org.). Perspectivas em Educação Histórica: actas das Jornadas Internacionais de Educação Histórica. Braga: Centro de Investigação em Educação da Universidade do Minho, 2001.

BARCA, I. Aula oficina: do Projeto à Avaliação. In: BARCA, I. (Org.). Para uma educação de qualidade: atas da quarta jornada de educação histórica. Braga, Centro de Investigação em Educação, 2004.

BOURDIEU, P. Coisas ditas. São Paulo: Editora Brasiliense, 2004.

BURKE, P. História e teoria social. São Paulo: UNESP, 2002.

CANDOTI, E.A. Projeto conhecer Londrina: práticas e vivências no contexto da cidade. In: LIMA, A.M.S. et al. (Org.). Diálogos entre as licenciaturas e a educação básica: aproximações e desafios. Londrina: UEL, 2013. p.159-168.

CERRI, L.F. Cidade e identidade. Região e ensino de História. In: ALEGRO, R.C. et al. (Org.). Temas e questões para o ensino de História do Paraná. Londrina: Eduel, 2013.

DIAS, P. As explicações de alunos sobre o conflito Israelo - Árabe: um estudo no $3^{\circ}$ ciclo do Ensino Básico. Rev. Currículo sem Fronteiras, v.7, n.1, p.86-114, 2007.

LE GOFF, J. Documento/monumento. Enciclopédia Einaldi. Lisboa: Imprensa Nacional/Casa da Moeda, 1984.

LE GOFF, J. História e memória. Campinas: UNICAMP, 1992. 
LIMA, L.P.; ZARPELÃO, S.H.M. O café em Londrina e no Paraná: abordagens para exploração do tema em sala de aula. In: ALEGRO, R.C. et al. (Org.). Temas e questões para o ensino de História do Paraná. Londrina: Eduel, 2013.

MENESES, U.T.B. O museu de cidade e a consciência de cidade. In: SANTOS, A.C.M.; KESSEL, C.G.: GUIMARAENS, C. (Org.). Museus \& cidades. Livro do Seminário Internacional "Museus e Cidades". Rio de Janeiro: Museu Histórico Nacional, 2003, p.255-282.

PERUZZO, C.M.K.; VOLPATO, M.O. Conceitos de comunidade, local e região: interrelações e diferença. Líbero, v.12, n.24, 2009. Disponível em: <http://www.revistas.univerciencia.org/index.php/libero/article/viewFile/6790/6132>. Acesso em 23 jun. 2016.

ROSADO, A.; SILVA, S. Conceitos básicos sobre avaliação das aprendizagens. Disponível em: <http://areas.fmh.utl.pt/ arosado/ESTAGIO/conceitos.htm>. Acesso em: 5 jun. 2016.

SIMAN, L.M.C. O papel dos mediadores culturais e da ação mediadora do professor no processo de construção do conhecimento histórico pelos alunos. In: ZARTH, P.A. et al. (Org.). Ensino de história e educação. Ijuí: UNIJUÍ, 2004.

SOUSA, R.G. A aula-oficina: um novo modo de ensinar história. Disponível em: $<$ http://educador.brasilescola.uol.com.br/estrategias-ensino/a-aula-oficina-um-novomodo-ensinar-historia.htm>. Acesso em: 23 jun. 2016.

ZAMBONI, E. Digressões sobre a educação e o ensino de história noi século XXI. História \& Ensino, v.11, 2005. Disponível em: $<$ http://www.uel.br/revistas/uel/index.php/histensino/article/view/11833>. Acesso em: 23 jun. 2016. 